\title{
EFECTOS DE LA DENSIDAD DE SIEMBRA Y FERTILIZACIÓN SOBRE LA BACTERIOSIS DEL PALMITO DE PEJIBAYE (Bactris gasipaes K.) ${ }^{1}$
}

\author{
Francisco Paulo Chaimsohn ${ }^{2}$, Jorge Mora-Urpî̉, Enrique Villalobos-Rodríguez ${ }^{4}$
}

\section{RESUMEN}

Efecto de la densidad de siembra y fertilización sobre la bacteriosis del palmito de pejibaye (Bactris gasipaes $\mathbf{K}$.). Se determinó el efecto de la densidad (3.333, 5.000 y 6.666 plantas/ha), el arreglo de siembra (rectangular y triangular) y el tipo de fertilización (químico, orgánico y químico-orgánico) sobre la incidencia y severidad de la enfermedad conocida como "bacteriosis del palmito", causada por la bacteria Pantoea stewartii (sin. Erwinia stewartii) y el hongo Fusarium sp, en el periodo de julio de 2004 a agosto de 2005, en Guápiles, Costa Rica. El porcentaje de incidencia de la enfermedad varió de 14,1 a $80,8 \%$. En las parcelas con el arreglo triangular hubo menor porcentaje de plantas enfermas. El porcentaje de incidencia de la bacteriosis fue mayor en las cepas de las parcelas fertilizadas con abono químico, seguido de aquellas fertilizadas con abono químico-orgánico y enmienda orgánica. La enfermedad se correlacionó de forma inversa a los contenidos de $\mathrm{Ca}, \mathrm{Mg}, \mathrm{Zn}, \mathrm{K}$ y Mn del suelo, y al contenido foliar de Mn. Por otra parte, se correlacionó de forma directa con el contenido de $\mathrm{Al}$ del suelo, con los contenidos foliares de $\mathrm{B}$ y $\mathrm{Cu}$, y con el porcentaje de interceptación de la radiación solar.

Palabras clave: Pejibaye, pupunha, palmito, Bactris gasipaes, Pantoea stewartii.

\begin{abstract}
Effects of plant population and fertilization type on the bacteriosis of the pejibaye palm heart (Bactris gasipaes K.). The incidence and severity of the plant disease known as "palm heart bacteriosis", caused by the bacteria Pantoea stewartii (syn. Erwinia stewartii) and the fungus Fusarium sp. was determined between July 2004 and August 2005 , as a function of plant density $(3,333 ; 5,000$; and 6,666 plants/ha), plant distribution (rectangular versus triangular) and fertilization type (chemical, organic and chemicalorganic), in Guápiles, Costa Rica. The incidence of the plant disease varied from 14.1 to $80.8 \%$. The percentage of diseased plants was lower in the plots planted with the triangular arrangement. The incidence of bacteriosis was higher in the plots fertilized with chemical fertilizer, followed by those fertilized with chemical-organic fertilizer and organic amendments. The incidence of the disease was negatively correlated with soil $\mathrm{Ca}, \mathrm{Mg}, \mathrm{Zn}, \mathrm{K}$, Mn contents, and leaf $\mathrm{Mn}$ content. A positive correlation with soil Al content, foliar $\mathrm{B}$ and $\mathrm{Cu}$ content, and degree of light interception, was also observed.
\end{abstract}

Key words: Pejibaye, pupunha, palm heart, Bactris gasipaes, Pantoea stewartii.

\section{INTRODUCCIÓN}

Actualmente la enfermedad conocida como "bacteriosis del palmito", es uno de los problemas fitosanitarios más relevantes en el cultivo del pejibaye para producción de palmito en Costa Rica. La dispersión, incidencia y severidad de la enfermedad están relacionadas con el mal manejo de las plantaciones

\footnotetext{
1 Recibido: 28 de mayo, 2007. Aceptado: 18 de enero, 2008. Parte del proyecto de investigación No 734-A3-160, "Análisis comparativo de sistemas de producción de palmito de pejibaye (Bactris gasipaes H.B.K.), modificando el arreglo de población y la fertilización de pejibaye". 2 Instituto Agronomico do Paraná, Brasil. Correo electrónico: fpchaimsohn@yahoo.com.br

3 Escuela de Biología, Universidad de Costa Rica. San José, Costa Rica. Correo electrónico: pejibaye@cariari.ucr.ac.cr

4 Centro de Investigación en Granos y Semillas, Universidad de Costa Rica. San José, Costa Rica. Correo electrónico: villalobos.enrique@ gmail.com
} 
y una fertilización inapropiada debido a los bajos precios pagados por el producto a partir de 1998.

En el año 2001, se estimó que el área afectada era del $27 \%$ del total del área cultivada (8.500 ha), equivalente a 2.295 hectáreas distribuidas principalmente en la zona Atlántica (Guápiles, Pococí y Siquirres) y en la zona Huetar Norte (Sarapiquí, Río Cuarto, Upala y San Carlos) (Olasso 2001).

Los posibles agentes patógenos de la enfermedad, mencionados en la literatura, son la bacteria Pantoea stewartii (sin. Erwinia stewartii) y el hongo Fusarium sp (Araya 2004, Mora Urpí et al. s.f.). En el caso específico del palmito, los agentes dispersores son la gotera del agua de lluvia y los picudos Metamasius hemipterus y Rhynchophorus palmarum (Mora Urpí et al. 2005, Mora Urpí et al. s.f.). Según estos autores, el picudo $M$. hemipterus es el principal agente propagador de la enfermedad en sentido horizontal; en tanto que, en la plantación, la gotera del agua de lluvia, solo la transmite en el sentido vertical y por ello es de menor importancia. Otros autores también reportaron insectos como los principales vectores de esta bacteria en maíz (Michener et al. 2002, CABI y EPPO 2005).

El estado nutricional de la planta y, consecuentemente, el tipo de fertilización puede influir en la incidencia y desarrollo de enfermedades (Marschner 1998; Huber 1990). Huber (1990) señala que el reconocimiento de los efectos de los nutrientes en las enfermedades está basado en la evidencia del efecto de la fertilización sobre la severidad de las enfermedades; la comparación de los contenidos de minerales en cultivares o tejidos resistentes y susceptibles; y la correlación entre las condiciones que influencian la disponibilidad de minerales con la incidencia y severidad de la enfermedad.

Asimismo, la aplicación de enmiendas orgánicas puede influir en la incidencia y severidad de enfermedades de diversas formas: por el suministro de nutrientes y otras sustancias químicas; por sus efectos en los microorganismos patógenos; por sus efectos en los microorganismos antagonistas a los patógenos que se encuentran en el suelo; y por los cambios que la materia orgánica puede causar en las propiedades físicas del suelo (Chaimsohn 2005).
Las condiciones climáticas y microclimáticas también afectan la diseminación y desarrollo de enfermedades en las plantas. De esta forma, la densidad y arreglo de siembra del cultivo pueden intervenir en la incidencia y severidad de la bacteriosis del palmito. Mora Urpí et al. (s.f.) señalan que la bacteriosis es un problema fitosanitario que involucra la participación de factores bióticos y abióticos y que el enfoque del estudio debe ser integral basado en el conocimiento del comportamiento de estos factores para desarrollar un método de control integrado.

Por haberse tornado la bacteriosis del palmito en un problema fitosanitario importante recientemente, hay pocos trabajos publicados sobre la diseminación o dinámica de la enfermedad en el campo. Este trabajo tuvo como objetivo evaluar la incidencia y severidad de la bacteriosis del palmito, en función de la densidad y disposición de las plantas y tipo de fertilización.

\section{MATERIALES Y MÉTODOS}

El estudio se desarrolló en una área experimental plantada con palmito de pejibaye (Bactris gasipaes Kunth), con diferentes densidades y disposiciones de siembra y fertilizado con abonos químicos y enmienda orgánica, en la Estación Experimental Los Diamantes, del Ministerio de Agricultura y Ganadería, ubicada en Guápiles, cantón Pococí, provincia de Limón; coordenadas $10^{\circ} 22^{\prime}$ latitud norte y $83^{\circ} 76^{\prime}$ longitud oeste a una altitud de $249 \mathrm{msnm}$. Durante el periodo de la realización de este trabajo, la temperatura promedio fue de $24,4{ }^{\circ} \mathrm{C}$ y la precipitación promedio anual fue de 4.222 $\mathrm{mm}$ (Figura 1). El suelo fue clasificado como un Andic Oxyaquic Dystrudepts de textura franco arenosa.

Se preparó el terreno con dos pasadas de arado y dos de rastra en enero del 2003. El manejo de malezas, fundamentalmente Paspalum fasciculatum Willd. ex Flügge, se hizo con glifosato. La siembra en el campo fue efectuada en los días 2 y 3 de octubre del 2003. El almácigo utilizado, de la variedad sin espinas Diamantes 10, tenía aproximadamente tres meses de germinado y dos pares de hojas formadas. Se continuó resembrando las plantas perdidas, de forma sistemática, hasta febrero de 2004. 


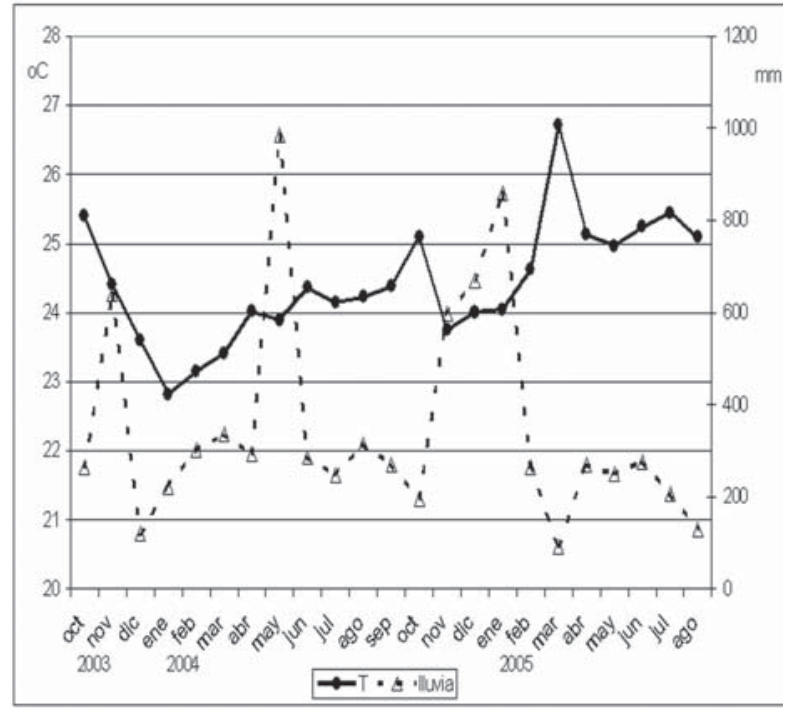

Figura 1. Temperatura media y precipitación mensuales. Estación Experimental Los Diamantes, Guápiles, Limón, Costa Rica. Octubre 2003-agosto 2005.

Se controlaron las malezas con chapeas y con aplicaciones de herbicidas (glifosato + 2,4 D). En noviembre de 2003 (40 días después de la siembra, dds) y en el periodo de enero a abril de 2004 (132 a 201 dds) se fertilizó mensualmente con fosfato diamónico (30 g/ planta), para promover el desarrollo de las raíces de las plantas y homogenizar la plantación experimental.

Los tratamientos evaluados fueron la combinación de densidades y arreglos de población con tipos de fertilización. Se utilizaron tres densidades de siembra: $3.333,5.000$ y 6.666 plantas/ha; dos arreglos de población: rectangular y triangular ("pata de gallo"); y tres tipos de fertilización: Testigo, que consistió en la aplicación de fertilizante químico, de acuerdo con la recomendación que se da para la Zona Atlántica de Costa Rica (Molina 2000), en función del análisis del suelo; Abono orgánico (compost): se ajustaron las cantidades de la enmienda orgánica a la concentración de nitrógeno de los abonos químicos utilizados; Abono mixto: este tratamiento consistió en aplicar una parte del fertilizante en forma orgánica y una parte en forma química, de acuerdo con los análisis del suelo y del compost.

Se utilizó un arreglo factorial de parcelas divididas, en un diseño de bloques completos al azar, con cuatro repeticiones, donde la parcela principal fue la densidad combinada con el arreglo y las subparcelas los tratamientos de fertilización. Las parcelas medían $200 \mathrm{~m}^{2}$ y el área experimental total fue de aproximadamente $4.800 \mathrm{~m}^{2}$.

El detalle de la aplicación de los fertilizantes químicos y enmiendas orgánicas es presentado en el Cuadro 1. Se aplicó un total de $8,5 \mathrm{~kg} /$ planta/año de enmienda orgánica, lo que correspondió a 28, 42 y 57 t/ha/año para las densidades de 3.333, 5.000 y 6.666 plantas/ha, respectivamente.

A partir del 22 de julio del 2004 (9,8 meses después de la siembra - mds) se inició la evaluación de la incidencia de la bacteriosis del palmito y, a partir de septiembre del mismo año, se inició la evaluación de la intensidad de dicha enfermedad. Se evaluaron las plantas de las dos primeras hileras útiles de cada subparcela, hasta enero del 2005, cuando se inició la cosecha. En febrero y en el período de abril a agosto del 2005 se evaluaron las cepas de las parcelas útiles

Cuadro 1. Fertilizantes químicos y enmiendas orgánicas utilizados en los tratamientos. Estación Experimental Los Diamantes, Guápiles, Limón, Costa Rica. Julio 2004 - agosto 2005.

\begin{tabular}{|c|c|c|c|c|}
\hline \multirow[b]{2}{*}{ dds } & \multirow[b]{2}{*}{ material $^{\dagger}$} & \multicolumn{3}{|c|}{ fertilización - g/planta } \\
\hline & & químico & orgánico & $\begin{array}{c}\text { quím.- } \\
\text { org. }\end{array}$ \\
\hline \multirow{3}{*}{68} & fosfato diamónico & 40 & - & 20 \\
\hline & - DAP & & & \\
\hline & boñiga & - & 2.000 & 1.000 \\
\hline \multirow{2}{*}{236} & $18-5-15-6-0,7$ & 30 & - & 15 \\
\hline & lombri compost (1) & - & 1.200 & 600 \\
\hline \multirow{2}{*}{335} & nitrato de amonio & 30 & - & 15 \\
\hline & lombri compost (2) & - & 2.000 & 1.000 \\
\hline \multirow{2}{*}{432} & $18-5-15-6-0,7$ & 100 & - & 50 \\
\hline & compost de palma (3) & - & 2.500 & 1.300 \\
\hline \multirow{2}{*}{523} & nitrato de amonio & 45 & - & 22,5 \\
\hline & lombri compost (2) & - & 3.000 & 1.500 \\
\hline \multirow{2}{*}{622} & $18-5-15-6-0,7$ & 110 & - & 55 \\
\hline & lombri compost (2) & - & 3.000 & 1.500 \\
\hline
\end{tabular}

dds - días después de la siembra

† (1) compost de la Estación Experimental Alfredo Volio Mata - Universidad de Costa Rica (UCR); (2) compost de Hacienda ganadera Pozo Azul, Río Frío; (3) compost de desecho de palma de aceite. 
(seis plantas por subparcela). La incidencia se expresó como porcentaje de plantas enfermas por subparcela; mientras que la severidad de la bacteriosis se determinó con base en la escala presentada en el Cuadro 2. Además, se determinó cuales hojas del tallo primario presentaban incidencia de la enfermedad, hasta la cosecha (16,5 mds). Para efectuar el análisis de varianza de la incidencia de la enfermedad por número (edad) de hoja ${ }^{5}$, se determinó un "Índice de Incidencia por Hoja" (IIH), el cual fue calculado con la fórmula:

$$
\begin{gathered}
I I H=(1 X \% \text { ho } 1-2)+(5 x \% \text { ho } 3-4)+(10 x \% \text { ho } 5-6)+ \\
(3 x \% \text { ho })+(1 x \% \text { ho } 8-9)
\end{gathered}
$$

Donde: \%ho $\mathrm{n}_{1}-\mathrm{n}_{2}=$ sumatoria del $\%$ de incidencia de la bacteriosis, expresado en número centesimal, en la hoja $n_{1} y_{2}$. De esta forma cuando:

$\mathrm{IIH} \cong 1$ : mayor incidencia en las hojas $1,2,8$ y 9 ;

$\mathrm{IIH} \cong 5$ : mayor incidencia en las hojas 3 y 4 ;

$\mathrm{IIH} \cong 10$ : mayor incidencia en las hojas 5 y 6 ;

$\mathrm{IIH} \cong 3$ : mayor incidencia en la hoja 7 .

Cuadro 2. Escala para determinar la severidad de la bacteriosis en palmito. Guápiles, Limón, Costa Rica. 2003.

\begin{tabular}{cc}
\hline puntos & \% cepa con síntoma aparente \\
\hline 0 & sin síntomas \\
1 & $1-10 \%$ \\
2 & $11-25 \%$ \\
3 & $26-50 \%$ \\
4 & $51-75 \%$ \\
5 & $76-100 \%$ \\
\hline
\end{tabular}

Con los datos de incidencia de la bacteriosis, en el período de agosto del 2004 a febrero del 2005, se calculó el Área Bajo la Curva del Desarrollo de la Enfermedad (ABC) Arauz (1998) y Arroyo (2004). Se correlacionó el $\mathrm{ABC}$ con los resultados de los análisis de suelo y foliar, además de la interceptación de luz, variables de crecimiento de las plantas, rendimiento del palmito, y porcentaje de infestación de picudo (Metamasius spp), con los que se determinaron los respectivos coeficientes de correlación.

\footnotetext{
5 La hoja 1 es la primera hoja abierta, siguiéndo la 2, 3, 4, etc.
}

El índice de severidad (SB) promedio del período de noviembre del 2004 a mayo del 2005 fue correlacionado con los resultados del análisis de suelo y foliar; mientras que el SB de enero del 2005 fue correlacionado con el porcentaje de interceptación de la RFA del mismo mes.

Se efectuó el análisis químico del suelo de todas las subparcelas del ensayo, a los 18 mds. Los análisis fueron hechos en el Laboratorio de Suelos del Ministerio de Agricultura y Ganadería y se determinó el pH, y los contenidos de materia orgánica, $\mathrm{Al}, \mathrm{Ca}, \mathrm{Mg}, \mathrm{K}$, $\mathrm{P}, \mathrm{Zn}, \mathrm{Mn}, \mathrm{Cu}, \mathrm{Fe}$. Para el diagnóstico foliar, hecho en la misma época del análisis de suelo, se procedió al muestreo en todas las plantas de la parcela útil de cada subparcela como es recomendado por Molina (2000). Los análisis también fueron efectuados en el laboratorio del MAG y se determinaron los contenidos de $\mathrm{N}$, P, K, Ca, Mg, Cu, Zn, Mn, Fe, B, y S.

El porcentaje de interceptación de la radiación fotosintéticamente activa (RFA) fue determinado mensualmente, en el periodo de julio de 2004 a enero de 2005. Se utilizó un radiómetro linear (Mod. LI - 191SA Line Quantum Sensor) y un radiómetro de punto (Modelo LI - 190SA Quantum Sensor) conectados a un acumulador de datos, "datalogger" (modelo LI - 1400 - LI-COR Inc.).

Las variables de crecimiento y fenología de la planta (altura, diámetro del tallo, número de hojas vivas y número de rebrotes), medidas a partir de los 6,5 mds, fueron determinadas cada tres meses conforme recomendaciones de Clement y Bovi (1999). También se procedió a evaluaciones dendrométricas y fenológicas el día anterior a las cosechas. En este caso, además de las variables ya indicadas, se midió la sección del pecíolo de la hoja más madura, como es sugerido por Corley y Breure (1981) para palma de aceite.

Se efectuó la cosecha de las plantas de la parcela útil aproximadamente 16,5 mds. Las variables evaluadas en el palmito fueron: longitud, diámetro promedio y pesos del palmito caulinar y foliar. También se calculó el rendimiento efectivo (peso promedio de palmito $\mathrm{x}$ $\%$ de palmito cosechado) y potencial (peso promedio de palmito $\mathrm{x}$ densidad de población) de palmito por ha. Cuando el palmito foliar presentó porciones estadísticamente significativas de diámetro diferente se determinó el diámetro y la longitud de cada porción. 


\section{RESULTADOS Y DISCUSIÓN}

Cuando se inició la evaluación de la bacteriosis (22 de julio del 2004), el porcentaje de incidencia promedio de la enfermedad era de $14,1 \%$, el cual aumentó hasta diciembre del 2004, alcanzando un valor promedio máximo de 80,8\% de plantas enfermas. Entre diciembre y febrero del 2005 hubo una drástica disminución en el porcentaje de incidencia de la enfermedad. Sin embargo, el porcentaje promedio de plantas enfermas aumentó de nuevo en abril y luego presentó variaciones hasta agosto, pero en ningún momento se redujo al nivel observado en febrero. Asimismo, la curva de incidencia promedio de la bacteriosis acompañó la curva de precipitación hasta febrero del 2005, cuando se efectuó el corte del tallo principal (Figura 2). A partir de la cosecha hubo un cambio importante en la morfología de la cepa, por el crecimiento de los rebrotes, lo que alteró el microclima dentro del área del cultivo y favoreció el desarrollo de la enfermedad.

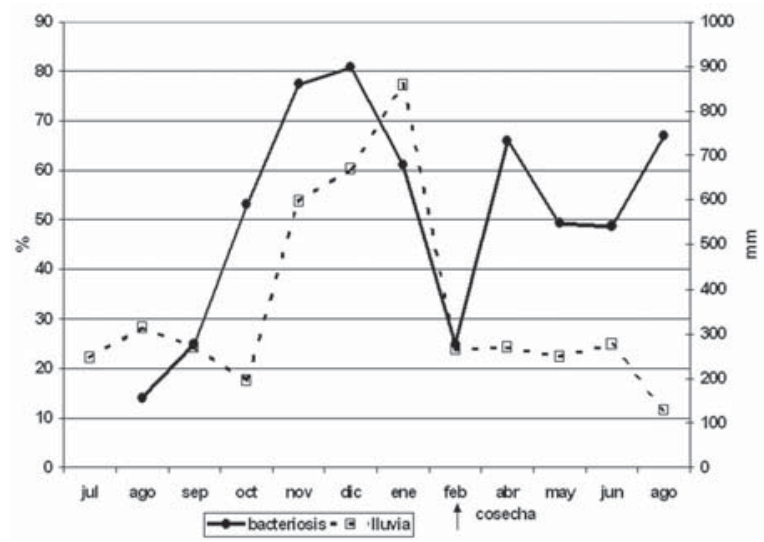

Figura 2. Porcentaje de la incidencia de la bacteriosis del palmito y precipitación. Estación Experimental Los Diamantes, Guápiles, Limón, Costa Rica. Julio 2004-agosto 2005.

Según Mora Urpí et al. (s.f.) la humedad juega un papel muy importante en el éxito de las inoculaciones de almácigos de pejibaye con los agentes causales de la bacteriosis. Estos autores constataron que la inoculación de la enfermedad, en almácigos de pejibaye, fue aproximadamente el doble más efectiva bajo condiciones de sombra y suelo saturado de humedad que a pleno sol y suelo con buen drenaje. Los mismos autores señalan que, en condiciones de campo, la infección posiblemente es reducida si las plantas no se encuentran húmedas por la lluvia al momento del contacto con los patógenos.

La densidad de siembra per se no influyó en el porcentaje de incidencia de la bacteriosis. Sin embargo, en octubre del 2004, el arreglo de siembra sí influyó $(\mathrm{P}=0,001)$ en esta variable. El porcentaje de plantas enfermas fue menor ente octubre del 2004 y enero del 2005 con el arreglo triangular (Figura 3). En agosto del 2005 (23 mds), también hubo efecto de la interacción entre la densidad y distribución de siembra $(\mathrm{P}=0,0206)$ en el porcentaje de incidencia de la bacteriosis. En las menores densidades de siembra, el porcentaje de plantas enfermas fue menor en las parcelas con ordenamiento rectangular, mientras que, en la población de 6.666 plantas/ha la incidencia fue menor en las plantas con distribución triangular (Figura 4).

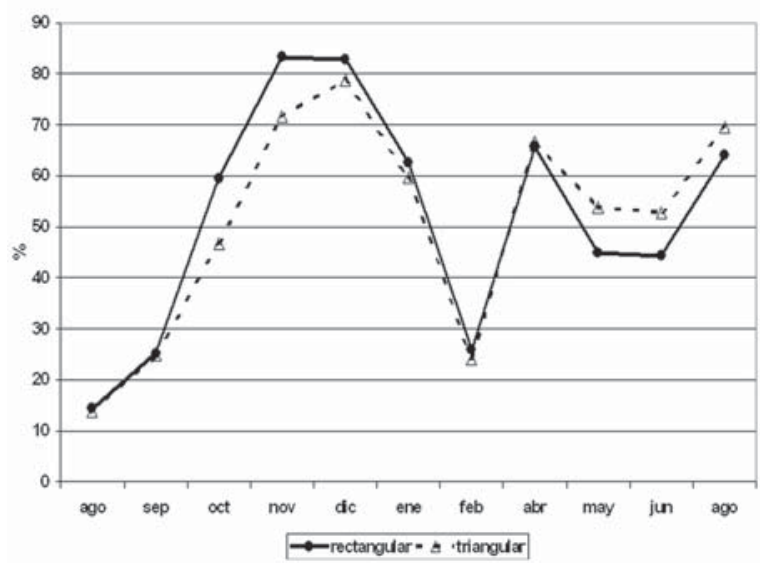

Figura 3. Incidencia de la bacteriosis del palmito en plantas cultivadas con dos tipos de distribución de población. Estación Experimental Los Diamantes, Guápiles, Limón, Costa Rica. Agosto 2004-agosto 2005.

El tipo de fertilización influyó en el porcentaje de incidencia de la enfermedad, en mayo y junio del 2005 ( $\mathrm{P}=0,0185$ y 0,0445 , respectivamente). En los dos meses, la incidencia de la bacteriosis fue mayor en las cepas de las parcelas fertilizadas con abonos químicos, seguido de aquellas fertilizadas con abono químico-orgánico y enmienda orgánica. En agosto del 2005 se mantuvo la misma tendencia observada en los 


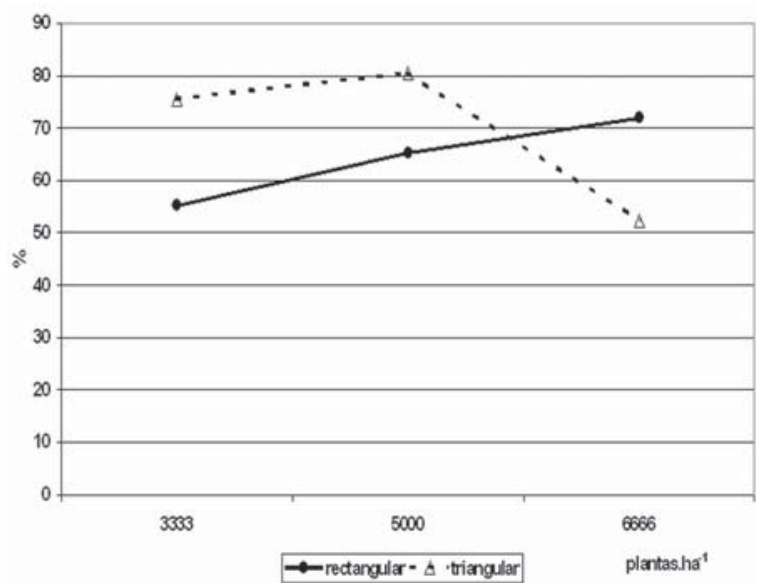

Figura 4. Incidencia de la bacteriosis del palmito en función de la densidad y distribución de población. Estación Experimental Los Diamantes, Guápiles, Limón, Costa Rica Agosto 2005.

meses anteriores, pero la diferencia de incidencia de la enfermedad en las plantas en que se aplicó el compost disminuyó con relación a las plantas fertilizadas con abono químico y químico-orgánico (Figura 5).

\section{Incidencia de la bacteriosis según el estado de maduración de la hoja}

La incidencia de la bacteriosis fue mayor en las hojas maduras. En gran parte del periodo evaluado (agosto, septiembre, noviembre y diciembre del 2004 y febrero del 2005), las hojas de las posiciones 4, 5 y 6 presentaron mayor porcentaje de hojas enfermas, con valores máximos para la hoja 5. En octubre de 2004, cuando se incrementó la incidencia de bacteriosis, las hojas de las posiciones 3,4 y 5 presentaron mayor incidencia de la enfermedad, con valores máximos en la hoja 4; mientras que, en enero de 2005 , cuando se redujo el porcentaje de incidencia de bacteriosis, las hojas 5,6 y 7 presentaron el mayor porcentaje de hojas enfermas, con valores máximos para la hoja 6 (Figura 6).

El Índice de Incidencia por Hoja (IIH) fue creciente de agosto a diciembre de 2004, disminuyó en enero y febrero de 2005 (Figura 7). Ambos posiblemente por causa de la distribución de las lluvias. La

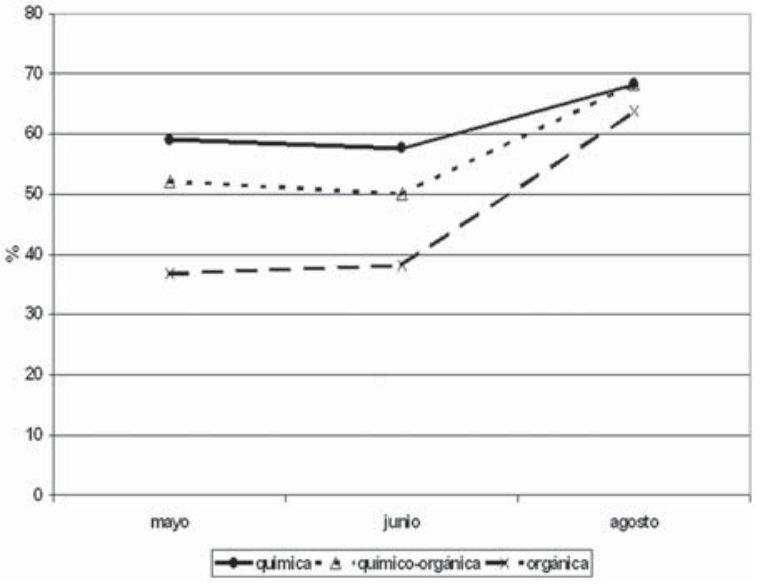

Figura 5. Incidencia de la bacteriosis del palmito en plantas cultivadas con fertilización orgánica, química y químico-orgánica. Estación Experimental Los Diamantes, Guápiles, Limón, Costa Rica. Mayo, junio y agosto 2005 .

densidad de siembra influyó en tal variable solamente en diciembre del 2004. Asimismo, la curva del IIH acompañó la curva del \% de incidencia de bacteriosis (Figura 7), indicando que cuanto mayor es el \% de incidencia de la enfermedad en la plantación, mayor es el porcentaje de hojas maduras con síntomas de la bacteriosis, tal como es de esperar.

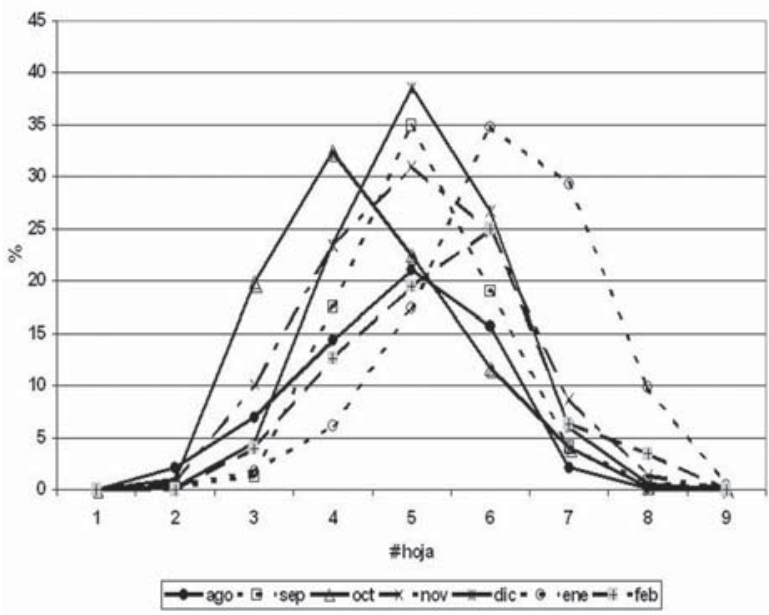

Figura 6. Incidencia de bacteriosis por edad de hoja. Estación Experimental Los Diamantes, Guápiles, Limón, Costa Rica. Agosto 2004 - febrero de 2005. 


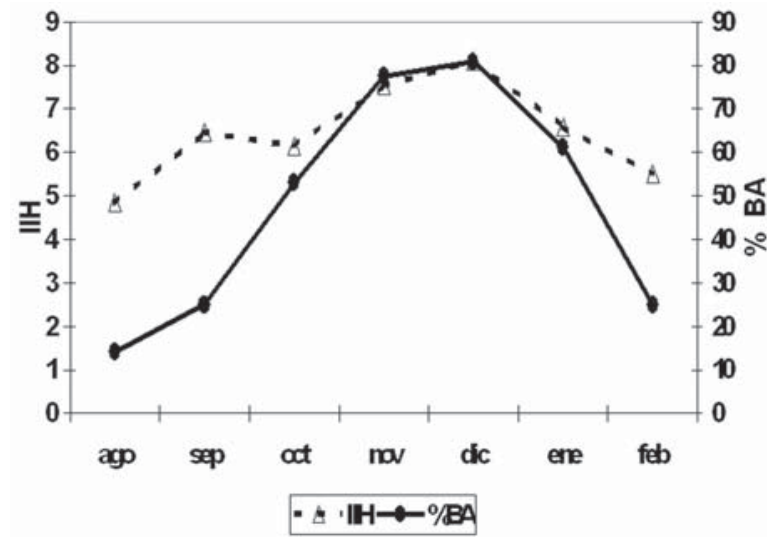

Figura 7. Porcentaje de incidencia de bacteriosis (\%BA) en la plantación e Índice de Incidencia de la bacteriosis por hoja (IIH). Estación Experimental Los Diamantes, Guápiles, Limón, Costa Rica. Agosto 2004 - febrero 2005.

Incidencia de la bacteriosis: Área Bajo la Curva (ABC)

La distribución de siembra influyó en el $\mathrm{ABC}(\mathrm{P}=$ $0,0459)$; además hubo un efecto de la interacción de la densidad por el arreglo de siembra $(P=0,0221)$ sobre la incidencia de la enfermedad. Se observó un valor promedio de 10.550 para la distribución rectangular y 9.514 para el arreglo triangular. En la mayor y menor densidad de siembra (6.666 y 3.333 plantas/ha) el $\mathrm{ABC}$ fue mayor con el arreglo rectangular; mientras que, en la densidad de siembra intermedia (5.000 plantas/ha) las plantas sembradas en arreglo triangular presentaran un mayor valor (Cuadro 3).

Hubo una tendencia de aumento del valor promedio del $\mathrm{ABC}$ con el incremento en la densidad (Figura 8). También se constató una tendencia de las plantas con fertilización químico-orgánica a presentar, en promedio, un valor menor que las plantas fertilizadas con abono químico u orgánico; los promedios fueron de $9.542,71 \pm 3.145,31,10.346,48 \pm 2792,54$ y $10.207,64$ $\pm 3.070,96$, respectivamente.

El ABC se correlacionó inversamente con los contenidos del suelo de $\mathrm{Ca}(\mathrm{r}=-0,601 ; \mathrm{P}=0,0001)$ y $\mathrm{Mg}$ $(r=-0,570 ; P=0,0001)$; en menor grado, también se correlacionó inversamente con los contenidos de: $\mathrm{Zn}(\mathrm{r}$
Cuadro 3. Área Bajo la Curva $(\mathrm{ABC})$ de incidencia de la bacteriosis del palmito, en función de la densidad, distribución de siembra y tipo de fertilización. Estación Experimental Los Diamantes, Guápiles, Limón, Costa Rica Julio 2004-agosto 2005.

\begin{tabular}{|c|c|c|c|}
\hline densidad pl/ha & distribución & fertilización & $\mathbf{A B C}$ \\
\hline \multirow{6}{*}{3.333} & rectangular & química & 10.873 \\
\hline & & orgánica & 10.525 \\
\hline & & químico-org. & 9.187 \\
\hline & triangular & química & 8.617 \\
\hline & & orgánica & 9.220 \\
\hline & & químico-org. & 8.378 \\
\hline \multirow{6}{*}{5.000} & rectangular & química & 11.061 \\
\hline & & orgánica & 9.217 \\
\hline & & químico-org. & 8.838 \\
\hline & triangular & química & 10.549 \\
\hline & & orgánica & 10.300 \\
\hline & & químico-org. & 11.192 \\
\hline \multirow{6}{*}{6.666} & rectangular & química & 11.347 \\
\hline & & orgánica & 11.975 \\
\hline & & químico-org. & 11.928 \\
\hline & triangular & química & 9.632 \\
\hline & & orgánica & 10.008 \\
\hline & & químico-org. & 7.734 \\
\hline \multicolumn{4}{|l|}{ ANDEVA } \\
\hline $\mathrm{D}$ & & & ns \\
\hline A & & & $*$ \\
\hline $\mathrm{D}^{*} \mathrm{~A}$ & & & $*$ \\
\hline F & & & ns \\
\hline
\end{tabular}

Nivel de significancia: $\mathrm{ns}=$ no significativo; $*=5 \%$.

$=-0,389 ; \mathrm{P}=0,0007), \mathrm{K}(\mathrm{r}=-0,312 ; \mathrm{P}=0,0076), \mathrm{yn}$ $(\mathrm{r}=-0,301 ; \mathrm{P}=0,0103)$. Aparentemente la acidez del suelo favorece la incidencia de la enfermedad, una vez que el contenido de $\mathrm{Al}$ se correlacionó positivamente con el $\mathrm{ABC}(\mathrm{r}=0,481 ; \mathrm{P}=0,0001)$ y el $\mathrm{pH}$ presentó correlación negativa $(r=-0,255 ; \mathrm{P}=0,0307)$ con el $\mathrm{ABC}$. Se menciona en la literatura que la nutrición mineral influye en la intensidad de la enfermedad; altos niveles de $\mathrm{N}$ amoniacal y $\mathrm{P}$ aumentan la susceptibilidad, mientras que altos contenidos de Ca y $\mathrm{K}$ tienden a disminuir la misma (CABI y EPPO, 2005). Según Villalobos y Killorn (2001) el Ca protege de la infección con Erwinia en varios cultivos agrícolas y de acuerdo con Marcshner (1998) la multiplicación y severidad 


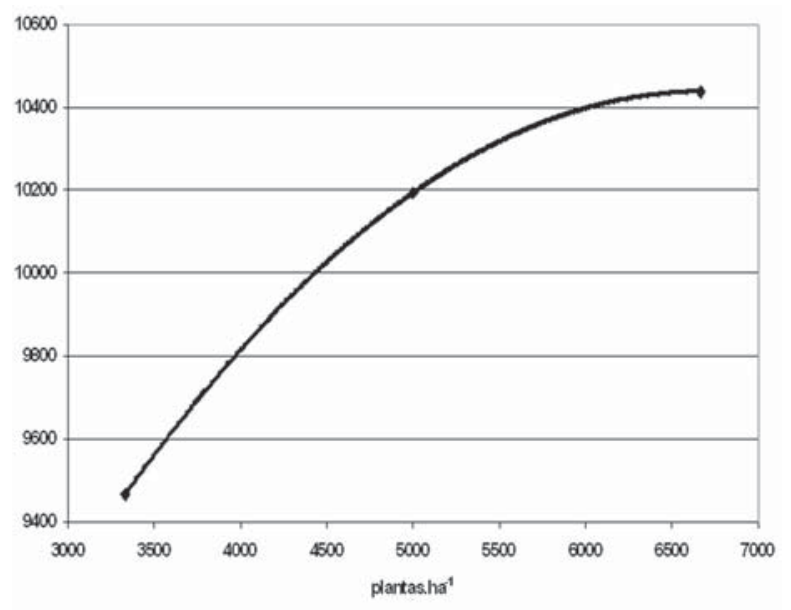

Figura 8. Área Bajo la Curva $(\mathrm{ABC})$ de incidencia de la bacteriosis en función de la densidad. Estación Experimental Los Diamantes, Guápiles, Limón, Costa Rica. Julio 2004-agosto 2005.

de determinadas enfermedades causadas por bacteria pueden ser más acentuadas cuando los contenidos de Ca y K son deficientes.

En relación con el diagnóstico foliar, el $\mathrm{ABC}$ se correlacionó negativamente con el contenido de $\mathrm{Mn}$ $(r=-0,508 ; P=0,0001)$ y positivamente con el contenido de $\mathrm{B}(\mathrm{r}=0,567 ; \mathrm{P}=0,0001)$ y $\mathrm{Cu}(\mathrm{r}=0,318$; $\mathrm{P}=0,0065)$. Sin embargo, Solórzano et al. (2002) encontraron que las plantas con menor incidencia de la enfermedad mostraron menor contenido foliar de $\mathrm{Mn}, \mathrm{Fe}$ y Zn.

El ABC también se correlacionó con el porcentaje de interceptación de la radiación fotosintéticamente activa (RFA) $(r=0,35224 ; P=0,0024)$. Esto se debe a que cuanto mayor es el porcentaje de RFA interceptada, menor es la radiación que pasa por el dosel, lo que proporciona un microclima más húmedo, que favorece la enfermedad. Esto se corroboró por la correlación entre el $\mathrm{ABC}$ y todos las variables de crecimiento: diámetro del tallo $(\mathrm{r}=0,373 ; \mathrm{P}=0,0013)$, altura de la planta $(\mathrm{r}=0,445 ; \mathrm{P}=0,0001)$, número de hojas $(\mathrm{r}$ $=0,452 ; \mathrm{P}=0,0001)$, y sección del pecíolo $(\mathrm{r}=0,399$; $\mathrm{P}=0,0005)$, lo que indica que la menor luminosidad dentro de la cepa, causada por el desarrollo de la planta, favoreció la incidencia de la enfermedad.
Sin embargo, los niveles observados de incidencia y severidad relativamente baja de la bacteriosis no interfirieron en el rendimiento de palmito. Se observa en el Cuadro 4 que el $\mathrm{ABC}$ se correlacionó con casi todos los componentes de rendimiento de palmito. El mayor valor del coeficiente de correlación (r) fue para el peso del palmito foliar, que es el principal componente del rendimiento de palmito de mayor valor comercial.

El ABC también se correlacionó positivamente con el porcentaje de infestación promedio del picudo del género Metamasius, entre noviembre de 2004 a febrero de 2005 ( $\mathrm{r}=0,544 ; \mathrm{P}=0,0001)$, lo que indica

Cuadro 4. Coeficiente de correlación de Pearson (r) y nivel de significancia (P) entre el ABC y los componentes de rendimiento del palmito caulinar y foliar. Estación Experimental Los Diamantes, Guápiles, Limón, Costa Rica Julio 2004-agosto 2005.

\begin{tabular}{clcc}
\hline \multirow{2}{*}{ palmito } & \multicolumn{2}{c}{ componente } & \multicolumn{2}{c}{ suelo } \\
\cline { 3 - 4 } & diámetro & $\mathbf{r}$ & $\mathbf{P}$ \\
\hline \multirow{3}{*}{} & largo & 0,304 & 0,0093 \\
& peso & 0,345 & 0,0030 \\
& rendimiento efectivo & 0,251 & 0,0333 \\
& rendimiento potencial & 0,319 & 0,0063 \\
\hline \multirow{3}{*}{} & diámetro & 0,351 & 0,0025 \\
& largo & 0,327 & 0,0050 \\
苛 & peso & 0,423 & 0,0002 \\
& rendimiento efectivo & 0,326 & 0,0052 \\
& rendimiento potencial & 0,369 & 0,0014 \\
\hline
\end{tabular}

la relación entre la diseminación del insecto con la incidencia de la enfermedad.

\section{Índice de severidad de la bacteriosis del palmito}

El Índice de severidad de la bacteriosis (ISB) se mantuvo relativamente bajo durante todo el período evaluado (noviembre del 2004 a agosto del 2005). Los valores promedio más altos fueron observados en la primera evaluación, correspondiendo a menos de $25 \%$ de la planta con síntomas de la enfermedad. Asimismo, el ISB acompañó la tendencia del porcentaje de incidencia de la enfermedad, con excepción de agosto 
de 2005, cuando el ISB se redujo y el porcentaje de la incidencia de la enfermedad se incrementó (Figura 9). Sin embargo, Vargas-Cartagena et al. (2002) observaron un desarrollo exponencial de la severidad de la enfermedad entre octubre y diciembre del 2002, con un $60 \%$ del área foliar afectada. Según los autores la temperatura además de la humedad relativa y la precipitación fueron determinantes en la severidad de la enfermedad.

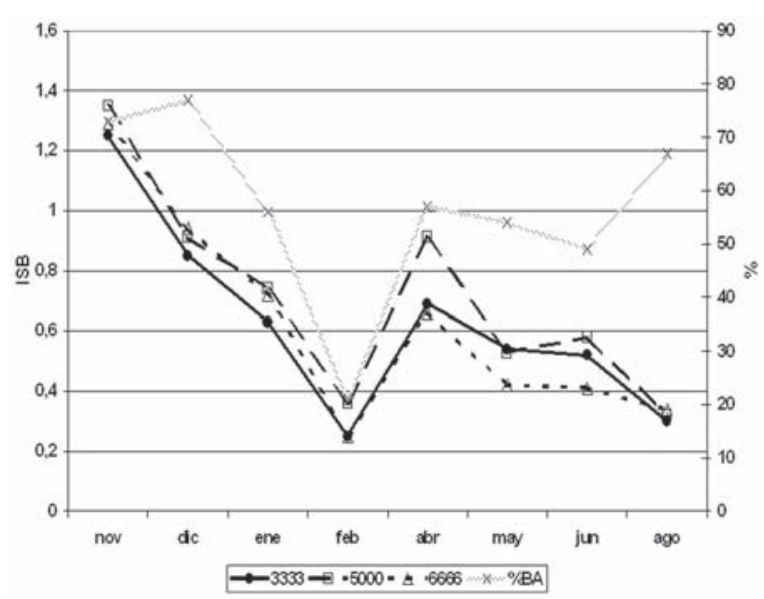

Figura 9. Índice de severidad de bacteriosis (ISB), en función de la densidad de siembra (plantas/ha) y porcentaje de incidencia de la enfermedad (\% BA). Estación Experimental Los Diamantes, Guápiles, Limón, Costa Rica. Noviembre 2004 -agosto de 2005.

En noviembre del año 2004 (13,3 mds), el tipo de arreglo influyó $(\mathrm{P}=0,0081)$ en el ISB; las cepas con distribución rectangular presentaron ISB superior en relación a las cepas sembradas con distribución triangular (1,46 y 1,13, respectivamente). Asimismo, en diciembre del 2004 (14,2 mds), hubo efecto de la interacción entre la densidad y arreglo de siembra ( $\mathrm{P}$ $=0,0059)$ en el ISB, y las plantas con distribución rectangular presentaron una tendencia de menor ISB que las cultivadas con distribución triangular. La fertilización influyó en el ISB en mayo del 2005, constatándose mayor ISB cuando se aplicó solamente abonos químicos, principalmente en las parcelas con menor densidad de siembra (Cuadro 5).
De forma similar al porcentaje de incidencia de la enfermedad, el índice de severidad (ISB) se correlacionó inversamente con los contenidos en el suelo de $\mathrm{Ca}(\mathrm{r}=-0,42837 ; \mathrm{P}=0,0002), \mathrm{Mg}(\mathrm{r}=-0,45814$; $\mathrm{P}=0,0001)$ y $\mathrm{K}(\mathrm{r}=-0,32549 ; \mathrm{P}=0,0053)$. El ISB también se correlacionó positivamente con el contenido de Al del suelo $(\mathrm{r}=0,34471 ; \mathrm{P}=0,003)$ y con $\operatorname{los}$ contenidos foliares de $\mathrm{B}(\mathrm{r}=0,48818 ; \mathrm{P}=0,0001)$ y $\mathrm{Cu}$ $(\mathrm{r}=0,36775 ; \mathrm{P}=0,0015)$. Asimismo, se constató una correlación negativa entre el ISB y el contenido foliar de $\mathrm{Mn}(\mathrm{r}=-0,45024 ; \mathrm{P}=0,0001)$.

La menor luminosidad dentro del cultivo, que propicia un microclima más húmedo, incrementó el índice de severidad de la enfermedad, una vez que el porcentaje de la RFA interceptada se correlacionó con el ISB $(r=0,39034 ; \mathrm{P}=0,0007)$.

\section{Diseminación y distribución espacial de la enfer- medad}

La incidencia de la enfermedad presentó una distribución espacial claramente diferenciada entre los bloques del ensayo, cuya localización es representada en el croquis de la Figura 10. El bloque I estaba ubicado cerca de otro experimento con pejibaye de la variedad Diamantes 10 (Bogantes 2003), mientras que el bloque II, estaba dispuesto cerca de un ensayo de variedades de pejibaye, incluyendo Diamantes 10 y palmito con espinas (Arroyo 2004), y de una área con pasto "king grass" (Pennisetum purpureum) cortado y amontonado, que constituía un criadero de picudos (Metamasius); el bloque III, además de estar cerca del pasto, estaba en una área en el cual las plantas sufrieron más el estrés hídrico (exceso de lluvia, seguido por déficit hídrico). Aparentemente, en el bloque IV las plantas sufrieron menos los efectos del estrés y están un poco más alejadas de las fuentes de inóculo de la enfermedad.

El porcentaje de incidencia de la bacteriosis fue superior en las parcelas de los bloques I y II hasta noviembre del 2004 (Figura 11), los cuales estaban más cerca de las fuentes de inóculo. Asimismo, el bloque II presentaba dos puntos que favorecen la diseminación 
Cuadro 5. Índice de severidad de bacteriosis del palmito, en función de la densidad y arreglo de siembra y tipo de fertilización. Estación Experimental Los Diamantes, Guápiles, Limón, Costa Rica. Noviembre 2004-agosto 2005.

\begin{tabular}{|c|c|c|c|c|c|c|c|c|c|}
\hline \multirow[t]{2}{*}{ D } & \multirow[t]{2}{*}{$\mathbf{A}$} & \multirow[b]{2}{*}{ fertilización } & \multicolumn{2}{|c|}{2004} & \multicolumn{5}{|c|}{2005} \\
\hline & & & nov & dic & ene & feb & abr & may & ago \\
\hline \multirow[t]{6}{*}{3.333} & $\mathrm{R}$ & química & 1,47 & 0,93 & 0,65 & 0,29 & 0,94 & 0,77 & 0,80 \\
\hline & & orgánica & 1,52 & 0,93 & 0,69 & 0,38 & 0,71 & 0,33 & 0,54 \\
\hline & & químico-org. & 1,35 & 0,84 & 0,62 & 0,29 & 0,54 & 0,50 & 0,56 \\
\hline & $\mathrm{T}$ & química & 0,91 & 0,79 & 0,67 & 0,25 & 0,75 & 0,75 & 0,96 \\
\hline & & orgánica & 1,18 & 0,82 & 0,63 & 0,13 & 0,40 & 0,29 & 0,61 \\
\hline & & químico-org. & 1,10 & 0,78 & 0,54 & 0,18 & 0,81 & 0,58 & 1,00 \\
\hline \multirow[t]{6}{*}{5.000} & $\mathrm{R}$ & química & 1,67 & 0,91 & 0,73 & 0,41 & 0,84 & 0,50 & 0,71 \\
\hline & & orgánica & 1,41 & 0,85 & 0,60 & 0,17 & 0,71 & 0,38 & 0,88 \\
\hline & & químico-org. & 1,15 & 0,75 & 0,73 & 0,32 & 0,79 & 0,29 & 0,53 \\
\hline & $\mathrm{T}$ & química & 1,36 & 0,91 & 0,80 & 0,40 & 1,04 & 0,86 & 0,92 \\
\hline & & orgánica & 1,32 & 1,00 & 0,78 & 0,42 & 0,90 & 0,37 & 0,77 \\
\hline & & químico-org. & 1,19 & 1,02 & 0,82 & 0,44 & 1,09 & 0,79 & 1,14 \\
\hline \multirow[t]{6}{*}{6.666} & $\mathrm{R}$ & química & 1,40 & 0,92 & 0,73 & 0,23 & 0,73 & 0,29 & 0,68 \\
\hline & & orgánica & 1,70 & 1,04 & 0,86 & 0,38 & 0,73 & 0,46 & 0,72 \\
\hline & & químico-org. & 1,50 & 1,12 & 0,78 & 0,29 & 0,67 & 0,54 & 0,95 \\
\hline & $\mathrm{T}$ & química & 1,12 & 0,73 & 0,77 & 0,33 & 0,65 & 0,42 & 0,54 \\
\hline & & orgánica & 1,16 & 1,08 & 0,71 & 0,21 & 0,61 & 0,38 & 0,66 \\
\hline & & químico-org. & 0,87 & 0,75 & 0,49 & 0,04 & 0,58 & 0,42 & 0,63 \\
\hline \multicolumn{10}{|l|}{ ANDEVA } \\
\hline $\mathrm{D}$ & & & ns & ns & ns & ns & ns & ns & ns \\
\hline A & & & $* *$ & ns & ns & ns & ns & ns & ns \\
\hline D*A & & & ns & $* *$ & ns & $\mathrm{ns}$ & ns & ns & $\mathrm{ns}$ \\
\hline $\mathrm{F}$ & & & ns & ns & ns & ns & ns & $*$ & ns \\
\hline $\mathrm{D} * \mathrm{~F}$ & & & ns & ns & ns & $\mathrm{ns}$ & ns & $\mathrm{ns}$ & ns \\
\hline
\end{tabular}

$\mathrm{D}=$ densidad de siembra (plantas.ha $\left.{ }^{-1}\right) ; \mathrm{A}=$ arreglo: $\mathrm{R}-$ rectangular, $\mathrm{T}-$ triangular

Nivel de significancia: $\mathrm{ns}=$ no significativo; $*=5 \% ; * *=1 \%$

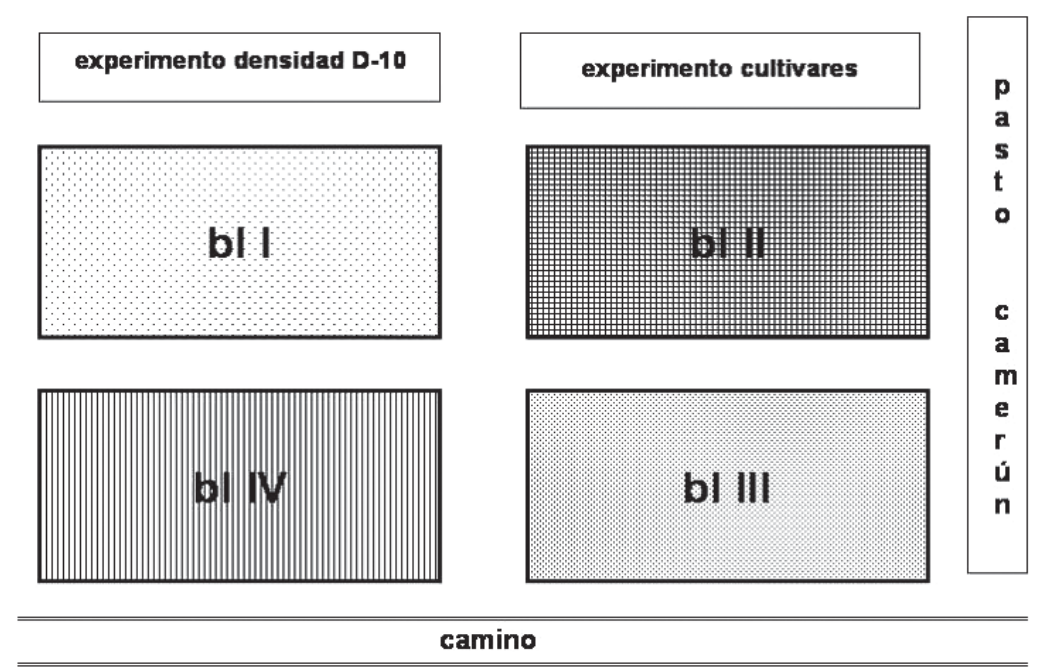

Figura 10. Localización de los bloques del ensayo de campo. Estación Experimental Los Diamantes, Guápiles, Limón, Costa Rica. Julio 2004-agosto 2005. 


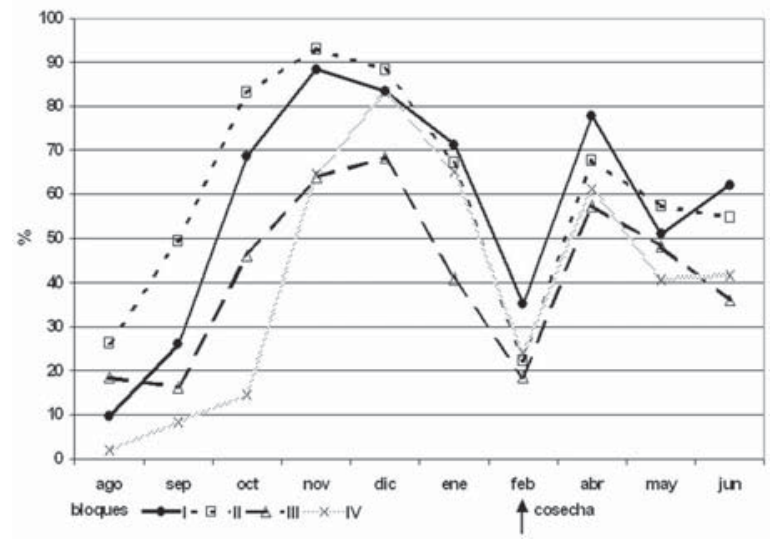

Figura 11. Incidencia de la bacteriosis del palmito por bloque. Estación Experimental Los Diamantes, Guápiles, Limón, Costa Rica. Agosto 2004 - junio de 2005.

de la enfermedad: la proximidad de cultivares más susceptibles (Utilis-Tucurrique) y del zacate, que es abrigo del picudo Metamasius hemipterus, agente diseminador de la bacteriosis.

En el bloque III, la incidencia de la enfermedad se mantuvo siempre menor, mientras que, en el bloque IV la incidencia fue similar a los bloques I y II de diciembre de 2004 a abril de 2005. Esto está relacionado a la diseminación de la bacteriosis en los bloques I y II y al mayor crecimiento de las plantas, que favorece la incidencia de la enfermedad por el microclima más húmedo en la plantación. La drástica reducción de la incidencia de la enfermedad en febrero está relacionada con la disminución de las lluvias (Figura 1) y con la cosecha del palmito, que causaran disminución de la humedad relativa en las parcelas.

\section{AGRADECIMIENTOS}

Los autores agradecen al CNPq-Brasil, por el otorgamiento de la beca de doctorado al primer autor, sin la cual este trabajo no se hubiera realizado. Al Centro de Investigación en Granos y Semillas de la Universidad de Costa Rica (UCR) por la indispensable ayuda financiera y logística. A la Vicerectoría de Investigación de la UCR por el apoyo financiero. A Guillermo Solano por el imprescindible apoyo en el trabajo de campo.

\section{LITERATURA CITADA}

Arauz, L.F. 1998. Fitopatología: un enfoque agroecológico. Editorial de la Universidad de Costa Rica, San José, C.R. 467 p,

Araya, SY. 2004. Optimización de las pruebas de patogenicidad para la confirmación del agente causal de la bacteriosis del palmito de pejibaye (Bactris gasipaes) en Costa Rica. Proyecto de Graduación, Facultad de Microbiología, San José, C.R., Universidad de Costa Rica. 59 p.

Arroyo, C. 2004. Fenología e incidencia de plagas en cuatro variedades de pejibaye (Bactris gasipaes) para producción de palmito en Guápiles, Costa Rica. Tesis Mag. Sc. San José, C.R., Universidad de Costa Rica. 124 p.

Bogantes, A. 2003. Evaluación de cuatro distancias de siembra y dos estrategias de control de malezas en pejibaye sin espinas (Bactris gasipaes K.) para palmito. Tesis Mag. Sc. San José, C.R., Universidad de Costa Rica. $91 \mathrm{p}$.

CABI y EPPO, 2005. Pantoea stewartii subsp. stewartii. Consultado 28 abril 2005. Disponible en: http://www. eppo.org/QUARANTINE/bacteria/Pantoea_stewartii/ ERWIST_ds.pdf

Chaimsohn, FP. 2005. Relaciones entre la fertilidad del suelo y el estado nutricional de las plantas con la incidencia de enfermedades biopatogénicas. San José, Universidad de Costa Rica, 24 p. Informe presentado al Curso de manejo integrado de suelos y cultivos tropicales (Mimeografiado).

Clement, CR; Bovi, MLA. 1999. Padronização de medidas de crescimento e produção em experimentos com pupunheiras para palmito. Acta Amazônica 30(3): 349 -362 .

Corley, RH; Breure, CJ. 1981. Measurements in oil palm experiments. Internal Report. London, Unilever Plantation Group. 35 p.

Huber, DM. 1990. Fertilizers and soil borne diseases. Soil Use and Management 6(4): 168 - 173. 
Marschner, H. 1998. Mineral nutrition of higher plants. 3 ed. Academic Press, San Diego. 889 p.

Michener, PM; Pataky, JK; White, DG. 2002. Transmission of Erwinia stewartii from plants to kernels and reactions of corn hybrids to stewart's wilt. Plant Disease 86(2): 167 - 172 .

Molina, E.A. 2000. Manual de suelos y nutrición de pejibaye para palmito. Asociación Costarricense de la Ciencia del Suelo, San José, C.R. 42 p.

Mora-Urpí, J; Arroyo, C; Mexzón, R; Bogantes, A. s.f. El proceso de infección en la "bacteriosis del palmito" de pejibaye (Bactris gasipaes Kunth). Universidad de Costa Rica, San José, C.R. 20 p. (mimeografiado).

Mora-Urpí, J; Sánchez, E; Wang, A; Uribe, L; Pizarro, R; Chaimsohn, FP; Vargas-Cartagena, L; Mexzón, R; Arroyo, C. 2005. Bacteriosis del palmito. CONICITUCR-INTA-PITTA-PEJIBAYE, San José, C.R. 22 p.

Olasso, A. 2001. Diagnóstico del estado actual de las plantaciones de palmito afectadas por bacteriosis en el cantón de Sarapiquí. Programa Nacional de Palmito. MAG. Costa Rica. (Mimeografiado). 26 p.

Solórzano, JA; Vargas-Cartagena, LV; Bonilla, OB; Piedra, R. 2002. Determinación del efecto de la aplicación de elementos menores, aminoácidos y ácidos húmicos sobre la incidencia y severidad de la bacteriosis del palmito de pejibaye. In: MAG Informe final Bacteriosis Palmito 2002 (versión final). San José, MAG. Consultado en 26 de noviembre de 2003. Disponible en: www.pejibaye.ucr.ac.cr

Vargas-Cartagena, LV; Solórzano, JA; Bonilla, OB; Iwasawa, H; Piedra, R. 2002. Determinación de la curva epidemiológica de la bacteriosis del palmito y su relación con las condiciones climáticas. In: MAG Informe final Bacteriosis Palmito 2002 (versión final). San José, MAG. Consultado 26 nov. de 2003. Disponible en: www.pejibaye.ucr.ac.cr

Villalobos, E; Killorn, R. 2001. Nutrición mineral. In: Villalobos, E. (ed. cient.). Fisiología de la producción de los cultivos tropicales. Editorial de la Universidad de Costa Rica Fascículo I. San José, C.R. p. 161 - 197. 